\title{
ON FLOW IN ESTUARIES
}

PART I

A critical review of some studies of slightly stratified estuaries

PART //

A slightly stratified turbulent flow

by

\section{H. RASMUSSEN}

Laboratory of applied mathematical physics The Technical University of Denmark

and

\section{J. B. HINWOOD}

Department of Mathematics

Nous reprenons, pour cet article, la présentation inaugurée dans le No 1-1972, qui permet une publication rapide d'articles présentant une partie mathématique importante.

LA HOUILLE BLANCHE. 
OA FLOH II ESTUARIES

PART I: A CRITICAL REVIEH OF SOHE STUDTES

OF SLICHTLY STFATIFIED ECTUARIES

\section{I.- INTRODUCIION.}

The flow in estuaries has tcen studied for many years, and significant progress has been made in freaicting the behaviour of sharply stratified (salt wedge) and unstratified (well mixei) types. In between these limiting cases are estuaries in which partial mixing of salt and fresh water occurs and in which there are continuous vertical and horizontal salinity gradients, typical of which is the coastal plain estuary of Pritchard.

Pritchara (1), (2) developed simplifiec equations to describe a coastal plain estuary, and these equations have been further developed and partially solveci by Rattray and hansen in a series of papers (3), (4) and (5). Hany coastal plain estuaries anci some other classes of estuaries are slifintly stratified, as defined in later sections, and for these cases the fhysical basis of Fritchara's mocel is reviewed. In the latter part of the praper the simplified equations used by ilansen and Rattray are obtained in a more systematics manner and the solutions they presented are discussed.

In a later paper in this series we will consider a more rigorous derivation of the mathematical model.

\section{Physicala desescription}

Cameron and Fritcharc $(6)$ cefine an estuary as follows: "an estuary is a semi-enclosec coastal bociy of water having a free connection with the open sea and within whicin the sea water is measurably diluted with fresh water derivine from land drainage". In this parer we discuss estuaries which are only slightly stratified, i.e. the vertical salinity gradient is small at any point of the estuary. This defination is more restrictive than that considered by Fritchara as it excludes estuaries where the vertical salinity Eradients are locally large even if their average over the depth is small. This type of estuary is usually produced when the mixing of fresh and salt water results mainly from the turbulence due to tidal motion. Other factors which contribute to the mixing are the shear stress at the bottom and the wind stress at the surface.

The basic non-tiadal or average circulation in estuaries of this type is shown in Fig. 1. The fresh water enters at the rignt and is graúually mixed with the salt water which enters at the left, mainly at the bottom. The average currents are cue to the entry of the fresh water and to the density difference between fresh and salt water. Thus the analysis constitutes a problem with features analogous to voth free ana forced convection. 'The problem has been considered by several authors, e.g. Arons anä Stormel (7), Ippen and ilarieran (8), and nobott (9), who have in their analyses suppressea one aspect of the problem by assuming a one-dimensional situation. The first treatrent which considered both 
aspects of the problem was given by Hansen (4) and Hansen and Rattray (5), but they did not consider the whole length of the estuary. A much earlier analysis by Ekman (10) Gave realistic flow patterns only because of wind stress, the gravitational term having been omitted in his arroximate equations of motion.

sea

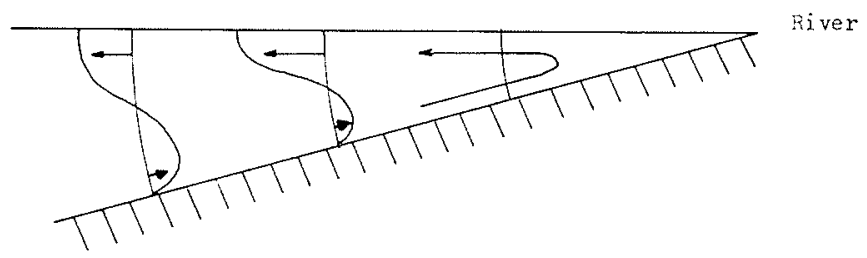

FIGURE I- SKETCI SHOUING NOI-TIDAL CIRCULATIOH AFTER EKMAV (10).
3. Vean equations of motion and continuity

In tris section we similify the mean equations of motio: and continuity by making some assumptions about the correlations between the mean velocity, the oscillating tidal velocity, and the turbulent fluctuations.

\section{Notation Used in Text} Kinematic eddy viscosity; $A^{*}=A / A_{O}$ where $A_{O}$ is a reperence value or $\dot{A}$. Breadth of estuary, taken as a f'unction of $x$ oniy; $i^{*}=3 / B_{0}$ where $B_{0}$ is a reference value of $\mathrm{i}$.

D Denth of estuary, taken as constant or as a function of $x$ onily.

F. Acceleration cue to eravity.

$k$ Constant in equation (4.6), witin units of (salinity) ${ }^{-1}$.

$K \quad$ Dirfusion coefficient for salt; $K_{z}, K_{X}, K_{x o}$ beinf vertical, jongitudinal and a reference value respectively.

L istuary length

$\check{L}_{0}, \check{L}_{1}, L_{2}$ Length scales used in equation $(5.8) ; \check{L}_{0}$ is used in section $\sigma$ with a different definition.

I. Pressure.

R River discharge per unit time.

5 Salinity (instantaneous value); $S_{\mathrm{F}}$ tical component of $S ; \mathrm{S}^{\prime}$ turivulent component of $s ; s^{*}=s / S_{0}$ where $S_{0}$ is a reference sainity .

t Time. 
Velocity (instantaneous value); u' turbulent component of $u$; u velocity vector.

$u$ Tidal component of $u$, having an amplitude $u_{0}$.

$x$ Longitudinai co-ordinate, measured positive seawards; $x_{0}$ is any reference value of $x$.

I Lateral co-ordinate.

z Vertical co-orainate, positive downwards from the surface.

a Exponent.

$\varepsilon \quad \varepsilon=k s$

c. Z̈on-äimensional longitudinal cooräinate.

$n_{1}, n_{1}, n_{2}$ Non-dimensional depth co-ordinates.

a A component of salinity.

$\checkmark \quad$ Constant.

5. Non-dimensional longitudinal co-ordinate,

$\rho$ Density; $\rho_{f}$ density of freshwater.

$\sigma \quad$ variable proportional to salinity difference.

i Winu stress.

$3 \quad$ ilon-dimensional stream function.

\% Stream function; $\psi^{*}=\psi^{*} \psi_{0}$ where $\psi_{0}$ is a reference value of $\Psi$ $\therefore \quad$ Angular velocity of the eartin.

$\Leftrightarrow \quad$ or superscrint ${ }^{-}$lime average over one or more tide cycles.

Consider a long and fairly narrow estuary, terms whose meaning will be defined later. Take the origin of co-ordinates in the free surface at the upstream limit of the estuary ana let $x$ be the lonGitudinal co-ordinate taken positive seawards, $y$ the lateral co-ordinate, and $z$ the vertical co-orìinate, positive downwards. Let $\left(u_{x}, u_{y}, u_{z}\right)$ and $\left(\Omega_{x}, \Omega_{y}, \Omega_{z}\right)$ be the velocity components and the components of the earth's rotation at any point in the estuary.

The three components of the equation of motion are

$\frac{\partial u_{x}}{\partial t}+u_{x} \frac{\partial u_{x}}{\partial x}+u_{y} \frac{\partial u_{x}}{\partial y}+u_{z} \frac{\partial u_{x}}{\partial z}=-\frac{1}{p} \frac{\partial p}{\partial x}-2\left[\Omega_{y} u_{z}-\Omega_{z} u_{y}\right]$

$\frac{\partial u_{y}}{\partial t}+u_{x} \frac{\partial u_{y}}{\partial x}+u_{y} \frac{\partial u_{y}}{\partial y}+u_{z} \frac{\partial u_{y}}{\partial z}=-\frac{1}{\partial} \frac{\partial p}{\partial y}-2\left[\Omega_{z} u_{x}-\Omega_{x} u_{z}\right]$

$\frac{\partial u_{z}}{\partial t}+u_{x} \frac{\partial u_{z}}{\partial x}+u_{y} \frac{\partial u_{z}}{\partial y}+u_{z} \frac{\partial u_{z}}{\partial z}=-\frac{1}{\rho} \frac{\partial p}{\partial z}-z-2\left[\Omega_{x} u_{y}-\Omega_{y} u_{x}\right]$

where $p$ is the pressure and $p$ the density. The viscous stress terms are not includied in these equations since it is known that they are smaller than the turbulent stress terms by several orders of magnitude (Cameron and Pritcnard (6), f. 319) and they may be regarded as being included in the Reynoids stresses in later equations.

Vertical accelerations may be neglected since they are typically in the order of $10^{-7} \mathrm{~ms}^{-2}$ whereas $g$ and $\frac{1}{0} \frac{\partial p}{\partial z}$ are approximately $10 \mathrm{~ms}^{-2}$, hence equation $(3.3)$ may be replaced by

$$
0=-\frac{1}{\rho} \cdot \frac{\partial p}{\partial z}-g
$$


ire shall express the velocity vector $u$ in the following

form

$$
\underline{u}=\underline{\vec{u}}+\underline{u}+\underline{u}^{\prime},
$$

Where $\bar{u}=$ the time mean velocity averaged over one or more tidal cycles,

$u=$ the tidal velocity, which is assumed to be the sum of simple harmonic functions of the tidal period $u_{x}, u_{y}, u_{z}$, with amplitudes $U_{o x}, U_{o y}, U_{o z}$ in directions $x, y, z$ respectively.

It has been shown by a number of workers, in particular Johns (11), that the oscillating tidal water level, in addition to causing an oscillating current, gives rise to a sinall residual current. this residual current is included in $\underline{\underline{u}}$ so that strictly $\underline{\underline{u}}$ is the oscillam tory part of the tidal velocity.

$u^{\prime}=$ the turbulent velocity fluctuation which are assured to have a time scale significantly smaller than the tidal period.

The equations of continuity for the turbulent, tidal and nean velocities are

$$
\begin{aligned}
& \frac{\partial u_{x}^{\prime}}{\partial x}+\frac{\partial u_{y}^{\prime}}{\partial y}+\frac{\partial u_{z}^{\prime}}{\partial z}=0, \\
& \frac{\partial u_{x}}{\partial x}+\frac{\partial u_{y}}{\partial y}+\frac{\partial u_{z}}{\partial z}=0, \\
& \frac{\partial u_{x}}{\partial x}+\frac{\partial \vec{u}_{y}}{\partial y}+\frac{\partial u_{z}}{\partial z}=0 .
\end{aligned}
$$

assuming water to be incompressible.

The time mean equations are obtained from equations (3.1) anà (3.2) by substituting for u and using equations (3.5), (3.6) ana (3.7). In tine operation of taking the time mean, terms of the type $\left.\bar{u}_{x} u_{y}^{\prime}\right\rangle$ and $\left\langle\bar{u}_{x} u_{y}\right\rangle$ where $>$ inaicates the time mean, are set equal to zero since by definition $\left\langle\vec{u}_{x} u_{y}^{\prime}\right\rangle=\vec{u}_{x}\left\langle u_{y}^{\prime}\right\rangle$ and $\left\langle u_{y}^{\prime}\right\rangle=0$ and similariy $\left\langle u_{y}\right\rangle=0$. It is assumed that terms of the type $\left\langle v_{x} u_{y}^{\prime}\right\rangle$ are equal to zero since there is no reason to sustect a correlation between the oscillating tialal motion and the turbulent velocity f'luctuations, although the mean square magnitude of the fluctuations will be Greatest during the period when $v_{x}$ is largest.

After averaging; the Coriolis forces appearing in equation (3.1) may be negiected since $\bar{u}_{z}$ is extremely small and $\bar{u}_{y}$ and $u_{y}$ are assumed to be zero because of the chosen snape of the estuary (Pritchara (2)). The mean equations of motion are then given by

$$
\begin{aligned}
& \frac{\partial \vec{u}_{x}}{\partial t}+\vec{u}_{x} \frac{\partial \bar{u}_{x}}{\partial x}+\vec{u}_{z} \frac{\partial \vec{u}_{x}}{\partial z}+\frac{\partial}{\partial x}\left\langle u_{x} u_{x}\right\rangle+\frac{\partial}{\partial z}\left\langle u_{x} u_{z}\right\rangle=-\left\langle\frac{\partial}{\partial} \frac{\partial p}{\partial x}\right\rangle \\
& -\frac{\partial}{\partial x}\left\langle u_{x}^{\prime} u_{x}^{\prime}\right\rangle-\frac{\partial}{\partial y}\left\langle u_{y}^{\prime} u_{x}^{\prime}\right\rangle-\frac{\partial}{\partial z}\left\langle u_{z}^{\prime} u_{x}^{\prime}\right\rangle,
\end{aligned}
$$

$\operatorname{anc\grave {~}}$

$$
0=-\left\langle\frac{1}{p} \frac{\partial p}{\partial y}\right\rangle-2 \Omega_{z} \vec{u}_{x}-\frac{\partial}{\partial x}\left\langle u_{x}^{\prime} u_{y}^{\prime}\right\rangle-\frac{\partial}{\partial y}\left\langle u_{y}^{\prime} u_{y}^{\prime}\right\rangle-\frac{\partial}{\partial z}\left\langle u_{z}^{\prime} u_{y}^{\prime}\right\rangle . \quad(3.9\rangle
$$


Equation (3.8) contains two terms involving the tiaal components of the velocity. Since $U_{x}$ has been assumed to be a simple harmonic function the first term is equivalent to $\frac{\partial}{\partial x}\left\langle U_{x} U_{x}\right\rangle=U_{O x} \frac{\partial U_{O x}}{\partial x}$. If,

as is frequently the case, the tidal wave is a progressive wave, $U_{x}$ and $U_{z}$ are $90^{\circ}$ out of phase, and the term $\frac{\partial}{\partial z}\left\langle U_{x} U_{z}\right\rangle$ disappears. A more

thorough discussion of this point is given in Appendix 1; the present line of reasoning has been adopted to obtain equations similar to those of the previous workers. With this assumption equation (3.8) becomes:-

$\frac{\partial \bar{u}_{x}}{\partial t}+\bar{u}_{x} \frac{\partial \vec{u}_{x}}{\partial x}+\bar{u}_{z} \frac{\partial \bar{u}_{x}}{\partial z}+u_{o x} \frac{\partial u_{o x}}{\partial x}=-\left\langle\frac{2}{\partial} \frac{\partial p_{x}}{\partial x}-\frac{\partial}{\partial x}\left\langle u_{x}^{\prime} u_{x}^{\prime}\right\rangle\right.$

$-\frac{\partial}{\partial y}\left\langle u_{y}^{\prime} u_{x}^{\prime}\right\rangle-\frac{\partial}{\partial z}\left\langle u_{z}^{\prime} u_{x}^{\prime}\right\rangle$.

Ne shall now formulate the equation for salt continuity. If we negुlect molecular diffusion on grounds that the turbulent diffusion is larger by several orders of magnitude, we have

$\frac{\partial S}{\partial t}=-\frac{\partial\left(u_{x} s\right)}{\partial x}-\frac{\partial\left(u_{y} s\right)}{\partial y}-\frac{\partial\left(u_{z} s\right)}{\partial z}$

where 3 is the salinity.

We assume tint the salinity can be expressed in the form $s=\bar{s}+s_{\mathrm{r}}+s^{\prime}$ where $\bar{S}=$ the mean salinity,

$S_{t r}=$ the periodic variation in salinity due to the tidal motion, which is assumed to be simple harmonic with amplitude $\mathrm{S}_{\mathrm{p}}$,

$S^{\prime}=$ the turbulent sluctuation in the salinity.

We can now suostitute equation (3.12) into equation (3.11) and by taking time average over several tidal cycles obtain the mean salinity equation. The types of terms in this equation which can be set equal to zero are $\frac{\partial}{\partial x}\left\langle U_{X} S_{T_{P}}>\right.$, since $u_{X}$ and $S_{T}$ are usually $90^{\circ}$ out of phase (Jowden (12), F. 27), $\frac{\partial}{\partial x}\left\langle\mathrm{u}_{\mathrm{x}} S^{\prime}\right\rangle$ and $\frac{\partial}{\partial \mathrm{x}}\left\langle\mathrm{S}_{n_{1}} u_{\mathrm{x}}^{\prime}\right\rangle$, since there is no reason to believe that there is ary correlation between the factors of these products (Cameron and Pritcharc (6), p. 322). Hence equation (3.11) becomes

$\left\langle\frac{\partial S}{\partial \vec{t}}\right\rangle \equiv \frac{\partial \bar{S}}{\partial t}=-\frac{\partial}{\partial x}-\left(\bar{u}_{x} \bar{S}\right)-\frac{\partial}{\partial y}\left(\bar{u}_{y} \vec{s}\right)-\frac{\partial}{\partial z}\left(\bar{u}_{z} \bar{s}\right)$

$-\frac{\partial}{\partial x}\left\langle u_{x}^{\prime} S^{\prime}\right\rangle-\frac{\partial}{\partial y}\left\langle u_{y}^{\prime} S^{\prime}\right\rangle-\frac{\partial}{\partial z}\left\langle u_{z}^{\prime} S^{\prime}\right\rangle$.

4. A Two-Dimensional Model of Esstuarine Flow

In (1) Pritchara wrote the salinity equation for the twodimensional flow in an estuary in which the breadth $B$ varies with $x$ and $z$ in the form:

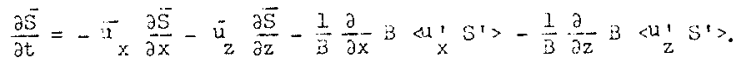


In order to obtain this equation he assumed none of the variables appearing were dependent upon $y$. He presented a more rigorous derivation of an equivalent equation in (13).

The equations of motion, (3.9) and (3.10), and tine two-dimensional equation of salt continuity (4.1) describe the flow in a stratified elongated estuary. Pritchara (1), (2) attempted to evaluate the relative importance of the different terms in these equations by using salinity and velocity data collected in the James River estuary in the summer of 1950 (Pritchara (14)). The general picture of salinity distribution in the James River is similar to that observed in many estuaries including the Thames (Inglis and Allen (15)), the Rotterdam Naterway (Rijkswaterstaat (16)) and ilewcastle Harbour (Hiznwood (17)).

The values of the terms in equation (4.1), the salt continuity equation, at different depths at one station are fiven in Fàle $I$. From this table we see that the horizontal convective term $\bar{u}_{x} \frac{\partial \vec{s}}{\partial x}$ and the vertical turbulent term $\frac{1}{B} \frac{\partial}{\partial z}\left(B\left\langle u_{z}^{\prime} S^{\prime}\right\rangle\right)$ are the dominant ones except near $z=3 \mathrm{~m}$ where $\bar{u}_{x}$ reverses direction and the vertical convective term $\vec{u}_{z} \frac{\partial \vec{S}}{\partial z}$ becomes important also. The time rate of change and the horizontal turbulent term are relatively small. Dyer (personal cormunication) nas pointed out that the evaluation of the two turbulence terms given in Table 1 requires the neglect of one term then the neglect of the other, however the results are believed to give correct orders of magnituace for each term. lable 1

Terms in tine salt continuity equation, after Pritciard (2), exvressed in

$$
E^{-3} s^{-1} \times 10^{4}
$$

\begin{tabular}{|c|c|c|c|c|c|}
\hline & & & & $\frac{2}{i} \frac{\partial}{\partial x}$ & $\frac{1}{3} \frac{\frac{\partial}{\partial z}}{\partial z}$ \\
\hline $\begin{array}{l}\text { Deptin } \\
\text { meters }\end{array}$ & $\frac{\partial \bar{S}}{\partial t}$ & $\bar{u}_{x} \frac{\partial \bar{S}}{\partial x}$ & $\bar{u}_{z} \frac{\partial \bar{S}}{\partial \bar{z}}$ & $B<u_{x}^{\prime} s^{\prime}>$ & $B\left\langle u_{z}^{\prime} s^{\prime}>\right.$ \\
\hline 0.0 & -4.2 & 484.0 & 0.0 & 1.3 & -431.2 \\
\hline 0.5 & -3.6 & 407.0 & $-\quad 1.0$ & 1.3 & -403.7 \\
\hline 1.0 & -1.0 & 326.0 & $-\quad 1.4$ & 1.3 & -324.9 \\
\hline 1.5 & 0.0 & 238.0 & $-\quad 1.9$ & 0.6 & -236.7 \\
\hline 2.0 & -0.1 & 159.0 & $-\quad 4.2$ & 0.2 & -154.9 \\
\hline 2.5 & 0.1 & 88.0 & -21.9 & -1.0 & -65.2 \\
\hline 3.0 & 0.8 & -8.0 & -117.0 & -0.8 & 125.0 \\
\hline 3.5 & 2.5 & -118.0 & -154.8 & -0.6 & 270.9 \\
\hline 4.0 & 4.6 & -219.0 & -81.0 & -0.0 & 295.8 \\
\hline 4.5 & 15.5 & -279.0 & -33.8 & -0.6 & 297.9 \\
\hline 5.0 & 14.5 & -288.0 & -13.7 & -0.4 & 287.6 \\
\hline 5.5 & 10.0 & -278.0 & $-\quad 9.2$ & -0.7 & 277.9 \\
\hline 6.0 & 10.5 & -278.0 & - $\quad 6.7$ & -1.2 & 275.4 \\
\hline 5.5 & 11.9 & -286.0 & $-\quad 5.2$ & -0.6 & 279.9 \\
\hline 7.0 & 12.0 & -318.0 & 3.5 & -1.0 & 303.5 \\
\hline 7.5 & 12.0 & -345.0 & 3.5 & -0.1 & 329.6 \\
\hline
\end{tabular}


Let us now consider the equations of motion (3.9) and (3.10). In his $1950^{\circ}$ paper (2), Pritchard argued that since the horizontal turbulent salt flux is small, as shown above, it woula be reasonable to assume by analogy that the horizontal components of the turbulent flux of momentum are also negligible compared to the other terms of (3.9) and (3.10). Argunent by analogy witn salt flux appears to be weak because the above term in equation (4.1) may be small merely because $u_{x}^{\prime}$ and $S^{\prime}$ are not correlated, however the conclusions appear reasonable from the following line of argument.

The turbulent flux terms in equation (3.10) are $\frac{\partial}{\partial x}\left\langle u_{x}^{\prime} u_{x}^{\prime}\right\rangle$ $+\frac{\partial}{\partial y}\left\langle u_{x}^{\prime} u_{y}^{\prime}\right\rangle+\frac{\partial}{\partial z}\left\langle u_{x}^{\prime} u_{z}^{\prime}\right\rangle$. Appropriate length scales for the changes in mean turbulence parameters will be the same as those for mean and tidal velocities, since these velocities give rise to the turbulence. Inus, since the fluctuating velocities are all of the same orcer of magnitude, the vertical term is likely to ve greater than the longitudinal and transverse terms by factors of $\mathrm{L} / \mathrm{D}$ and $\mathrm{B} / \mathrm{D}$ respectively, where $\mathrm{L}$ is the length of the estuary. Very near the channel boundaries the turbulence will show pronouncea anisotrony anä this argument will not be correct, but it will be valid throughout most of the estuary. Thus equation (3.10) becomes

$\bar{u}_{x} \frac{\partial \vec{u}_{x}}{\partial x}+\bar{u}_{z} \frac{\partial \bar{u}_{x}}{\partial z}+v_{o x} \frac{\partial v_{o x}}{\partial x}=-\left\langle\frac{\partial}{p} \frac{\partial p}{\partial x}\right\rangle-\frac{\partial}{\partial z}\left\langle u_{z}^{\prime} u_{x}^{\prime}\right\rangle$.

Pritchard also assured that equation (3.4) applied, and after averafing he obtained the following:

$\frac{1}{\rho} \frac{\partial \bar{p}}{\partial z}-g=0$

He then solved equations (4.2) and (4.3) for the shear stress term $\frac{\partial}{\partial z}\left\langle\mathfrak{u}^{\prime}{ }^{u^{\prime}}{ }^{\prime}{ }^{\prime}\right.$. He made the physically reasonable assumptions that this stress was zero at the surface and could be estimated at the bottom from the PrandtI-von Karman boundary layer theory for a rough boundery with a roughness height of $0.02 \mathrm{~cm}$. The shear stress could then be evaluated, and the relative importance of the different terms in (4.2) could be determined. The results of these calculations are given in Table 2.

Fritchard's assurption of $0.02 \mathrm{~cm}$, although reasonable is quite critical and his shear stress values could easily be $50 \%$ or more in error. Assuming that he calculated the bed shear stress from a mean valocity measured $0.5 \mathrm{~m}$ above the bed, then a roughness height of $0.13 \mathrm{~cm}$, which he cites as appropriate for a sandy bed, results in the shear stress being increased by a factor of $5 \frac{1}{2}$, and alters the computed horizontal pressure gradients. 
Table_?

Variation with cepth of the terms in the longitudinal component of the mean equation of motion for a typical section in the James River, after Pritchard (2), expressed in $\mathrm{m} \mathrm{s}^{-2} \times 10^{6}$

\begin{tabular}{cccccc}
$\begin{array}{l}\text { Depth } \\
\text { meters }\end{array}$ & $\bar{u}_{x} \frac{\partial \bar{u}_{x}}{\partial x}$ & $\bar{u}_{z} \frac{\partial \bar{u}_{x}}{\partial z}$ & $v_{o x} \frac{\partial v_{o x}}{\partial x}$ & $-<\frac{1}{p} \frac{\partial p}{\partial x}$ & $\frac{\partial}{\partial z}\left\langle u_{z}^{\prime} u_{x}^{\prime}\right\rangle$ \\
\hline 0 & 0.03 & 0.01 & 2.97 & 14.30 & 11.29 \\
1 & 0.12 & 0.09 & 2.97 & 10.56 & 7.33 \\
2 & 0.08 & 0.28 & 2.97 & 6.03 & 3.50 \\
3 & 0.01 & 0.42 & 2.97 & 3.10 & -0.30 \\
4 & 0.09 & 0.20 & 2.97 & -0.64 & -3.90 \\
5 & 0.21 & 0.04 & 2.97 & -4.38 & -7.50 \\
6 & -0.04 & 0.01 & 2.97 & -8.09 & -11.03 \\
7 & -0.04 & 0.02 & 2.97 & -11.77 & -14.72 \\
\hline
\end{tabular}

The convective terms in equation (4.2) are shown in table 2 to be negiigible in comparison with the other terms. Hence equation (4,2) may be written as

$$
v_{o x} \frac{\partial U_{o x}}{\partial x}=-\left\langle\frac{1}{\partial} \frac{\partial p}{\partial x}-\frac{\partial}{\partial z}\left\langle u_{z}^{\prime} u_{x}^{\prime}\right\rangle\right.
$$

If the time-mean varinules and parameters are assumed not to vary across the flow, the roint equations (4.1) and (4.4) will
De unchanged on integration across the breadth of the estuary and equation (3.7) will become

$$
\frac{\partial}{\partial x} B \vec{u}_{x}+\frac{\partial}{\partial z} B \vec{u}_{z}=0
$$

Thus Pritchara's equations (4.1) and (4.4), together with the continuity equation $(4,5)$ and appropriate boundary conditions form a matinematical model of an elongated estuary of gradually varying breadth in which the variables and parameters are assumed not to vary across the breadth. Two more relationships are required. 'The first is an equation of state which relates $\rho$ and $\mathrm{S}$. For the type of estuary we are considering the following expression can be used:

$$
\rho=\rho_{f}(I+k S)
$$

where $\rho_{f}$ is the density of fresh water and $k$ is a constant. The second is a relationship between the mean and the turbulence quantities such as the eddy coefficients introciuced in the next section.

\section{Development of the model}

In oreer to treat the model developed in the previous section, it is necessary to simplify it. It is usual to relate the shear stress to the mean velocity gradient by a coefficient of eddy viscosity, $A$, defined by

$$
\left\langle u_{z}^{\prime} u_{x}^{\prime}\right\rangle=-A \frac{\partial \ddot{u}_{x}}{\partial z}
$$


Thus equation $(4.4)$ becomes

$$
U_{o x} \frac{\partial U_{o x}}{\partial x}=-<\frac{l}{p} \frac{\partial p}{\partial x}+\frac{\partial}{\partial z} \quad\left(A \frac{\partial \vec{u}_{x}}{\partial z}\right)
$$

Similarly the turbulent fluxes of salt are related to the mean salinity Eradients by coefficients of eddy diffusion, $K_{x}$ and $K_{z}$, defined by

$$
\begin{aligned}
& \left\langle u_{x}^{\prime} S^{\prime}\right\rangle=-K_{x} \frac{\partial \bar{S}}{\partial x}, \\
& \left\langle u_{z}^{\prime} S^{\prime}\right\rangle=-K_{z} \frac{\partial \bar{S}}{\partial z} .
\end{aligned}
$$

In general the eddy coefficients are not constants, but are functions of position and the parameters of the flow taking appropriate values at each point. For steady conditions equation $(4.1)$ becomes

$$
\bar{u}_{x} \frac{\partial \bar{S}}{\partial x}+\bar{u}_{z} \frac{\partial \bar{S}}{\partial z}=\frac{1}{B} \frac{\partial}{\partial x}\left(B \kappa_{x} \frac{\partial \bar{S}}{\partial x}\right)+\frac{1}{B} \frac{\partial}{\partial z} \cdot\left(B K_{z} \frac{\partial \bar{S}}{\partial z}\right) \cdot(5.5)
$$

From the results in Table 1 we can deduce that the term containing $K_{x}$ must usually be fairly small compared to the term containing $\mathrm{K}_{\mathrm{z}}$.

Further simplifications were obtained by Hansen and Rattray who reduced the equation of motion to a linear equation. A more rigorous reduction is given below. The resulting equation is partly obtained by differentiation of the simplified equations (4.3) and (5.2), and it is by no means certain that the derivatives of the terms neglected in obtaining the latter equations are also negligible. A more rigorous procedure is to consider the order of magnitude of terms after all differentiation; this will be aiscussed in a later paper in this series.

The first such simplification is to remove the pressure from equations (4.3) and (5.2). The difficulty in doing this is that the pressure appears in (4.3) in the forni $\frac{\lambda}{\bar{p}} \frac{\partial \bar{p}}{\partial x}$ while in (5.2) it appears in the form $<\frac{1}{p} \frac{\partial p}{\partial x}$. By assuming that there is no correlation between $\rho^{\prime}$ and $p^{\prime}$ or from the arguments presented in Appendix 2 it may be shown with sufficient accuracy, that

$$
<\frac{1}{\rho} \frac{\partial p}{\partial x}=\frac{1}{\rho} \frac{\partial p}{\partial x}
$$

Which is implicitly assumed in the three papers by Hansen and Rattray.

$$
\text { The equation (4.5) can be satisfied by a stream- }
$$

function $\psi$ defined by $\frac{\partial \psi}{\partial z}=-B \bar{u}_{x}, \frac{\partial \psi}{\partial x}=B \bar{u}_{z}$. If $p$ and $\rho$ are eliminated from equations (4.3) and $(5.2)$ using $(5.6)$ and the equation of state (4.6) we obtain after some manipulation and by using the fact that the tidal term is independent of $z$ (Table 2):

$$
\begin{aligned}
U_{O x} \frac{\partial U_{o x}}{\partial x} \times \frac{\partial \bar{S}}{\partial z}+\frac{\partial^{2}}{\partial z^{2}} & {\left[A \frac{\partial}{\partial z}\left(\frac{1}{B} \frac{\partial \psi}{\partial z}\right)\right] } \\
& +k \frac{\partial}{\partial z}\left\{\bar{S} \frac{\partial}{\partial z}\left[A \frac{\partial}{\partial z}\left(\frac{1}{\bar{B}} \frac{\partial \psi}{\partial z}\right)\right]\right\}+g k \frac{\partial \bar{S}}{\partial x}=0 .
\end{aligned}
$$


are șatisfied. In order to obtain these conditions we shall nondimensionalize (5.7) by defining new variables as follows:

$$
\begin{aligned}
& \psi=\psi_{0} \psi^{*}, \bar{s}=S_{0} s^{*}, \quad z=L_{1} \pi_{1}, \\
& x=L_{0} \xi, z=L_{2} n_{2} .
\end{aligned}
$$

Here $\psi_{0}$ and $S_{0}$ are reference values of $\psi$ and $S, L_{0}$ the length scale for horizontal variation in $\bar{S}, L_{1}$ the length scale for vertical variation in $\psi$, and $\mathrm{I}_{2}$ the length scale for vertical variation in $\overrightarrow{\mathrm{S}}$. It seems reasonable to suppose that $L_{1}$ is of the same order of magnitude as the depth of the estuary, while $\mathrm{L}_{2}$ may possibly be very much smallex if there is a thin layer in which the salinity varies rapialy. We shall also write

$$
A=A_{0} A^{*}, B=B_{0} B^{*},
$$

where $A_{0}$ and $B_{0}$ are reference values of $A$ and $B$.

In terms of these variables and parameters equation (5.7)

becomes

$\frac{\partial^{2}}{\partial n_{1}}\left[A^{*} \frac{\partial}{\partial n_{1}}\left(\frac{1}{B^{*}} \frac{\partial \psi^{*}}{\partial n_{1}}\right)\right]+k S_{0} s^{*} \frac{\partial^{2}}{\partial n_{1}^{2}}\left[A^{*} \frac{\partial}{\partial \eta_{1}}\left(\frac{l}{B^{*}} \frac{\partial \psi^{*}}{\partial n_{1}}\right)\right]$

$+k S_{0} \frac{L_{1}}{L_{2}} \frac{\partial S^{*}}{\partial n_{2}} \frac{\partial}{\partial n_{1}}\left[A^{*} \frac{\partial}{\partial n_{1}}\left(\frac{I}{B^{*}} \frac{\partial \psi^{*}}{\partial n_{1}}\right)\right]$
$+U_{o x} \frac{\partial U_{o x}}{\partial x} \frac{B_{0} L_{1}^{4} k S}{A_{0} L_{2} \psi_{0}} \frac{\partial S^{*}}{\partial n_{2}}+\frac{g k S_{0} B_{0} L_{1}^{4}}{\psi_{0} A_{0} L_{0}} \frac{\partial S^{*}}{\partial \xi}=0$.

In comparison with the first term, the second term is of lower order of magnitude since $k S_{0} \ll 1$. The suppression of this term can be called a Boussinesq type approximation. The third term, however, requires more discussion. This term can oniy be ignored if $\mathrm{L}_{1} / \mathrm{L}_{2}$ is of order 1 , but if there are parts of the estuary in which the vertical salinity gradient varies relatively rapidly over a length smail compared $L_{1}$ the ratio $L_{1} / L_{2}$ would be large. Hence $\mathrm{KS}_{0}\left(L_{1} / L_{2}\right)$ coula be of order $I$, anä in this case the third term would have to be retained. To ensure that $k S_{0}\left(L_{1} / L_{2}\right)<<$ this paper is restrictea to slightly stratified estuaries, i.e. with no strong salinity gradients at any point. The restriction of small salinity gradients allows us to omit the product of the tidal acceleration and the vertical salin-

ity gradient in equation (5.8). The restriction imposed is that

$$
U_{o x} \frac{\partial U_{o x}}{\partial x} \frac{B_{0} L_{1}^{4} k S_{0}}{A_{0} L_{2} \psi_{0}} \ll 1
$$

or an equivalent but more complete expression obtainable from the results of Appenãix 2.

Thus in a slightly stratified estuary equation (5.8)

may be reduced to

$$
\frac{\partial^{2}}{\partial z^{2}}\left[A \frac{\partial}{\partial z}\left(\frac{1}{B} \frac{\partial \psi}{\partial z}\right)\right]+g k \frac{\partial \bar{S}}{\partial x}=0 .
$$


In terms of the stream function $\psi$, the salt continuity equation (5.5) becomes

$$
\frac{\partial \psi}{\partial x} \frac{\partial \bar{S}}{\partial z}-\frac{\partial \psi}{\partial z} \frac{\partial \bar{S}}{\partial x}=\frac{\partial}{\partial x}\left(B K_{x} \frac{\partial \bar{S}}{\partial x}\right)+\frac{\partial}{\partial z}\left(3 K_{z} \frac{\partial \bar{S}}{\partial z}\right) .
$$

The velocity components and the salinity must satisfy certain conditions at the boundaries. Only the conditions at the surface and the bottom will be given here; these conditions are

1) the net transport is equal to the river flow $R$,

2) the shear stress at the surface is equal to the wind stress,

3) there is no normal flow and no slip at the bottom $z=D(x)$,

4) the normal salt flux is zero at the surface and the bottom, or equivalently, the salt flux is zero across any section and is zero at either the surface or the bottom.

Thus we have

$$
\begin{aligned}
& \psi=R, \frac{\partial}{\partial z}\left(\frac{1}{B} \frac{\partial \psi}{\partial z}\right)=\frac{\tau}{\rho_{f^{A}}} \text { at } z=0, \\
& \psi=-\frac{\partial \psi}{\partial z}+\frac{\partial \psi}{\partial x} \frac{d D}{d x}=0 \quad \text { at } z=D(x),
\end{aligned}
$$

and any two of

$$
K_{z} \frac{\partial \bar{S}}{\partial z}-K_{x} \frac{\partial \bar{S}}{\partial x} \frac{d D}{d x}=0 \quad \text { at } z=D(x)
$$

$$
\begin{aligned}
& E K_{z} \frac{\partial \bar{S}}{\partial z}=0 \quad \text { at } z=0, \\
& \int^{S}\left(\bar{S} \frac{\partial \psi}{\partial z}+B K_{z} \frac{\partial \bar{S}}{\partial x}\right) d z=0 .
\end{aligned}
$$

It must be pointed out that since the viscous terms no longer appear explicitly in equation (5.9) the use of the no slip condition restricts the choice of eddy viscosities and may introduce difficulties in the analysis.

\section{Similarity solutions}

Similarity solutions of the model derived in the previous section have been obtaineà by Rattray anả Hansen (3), Hansen (4), and Hansen and Rattray (5). Before we discuss these solutions it is necessary to remark that although they attribute their longitudinal equation of motion to Pritchard they write an equation similar to (5.2) differently in each paper. These aifferences are in the definition of the eddy viscosity and in the form of the tidal term, and necessitate various assumptions in order to arrive at equation (5.9).

Based on Pritchard's data, Hansen and Rattray (5) divided the estuary into the three regions shown in Figure 2. The other data cited in Section 4 snow the same trends, and although the regions merge into each other such a division appears to be reasonable. It is to be regretted that this expeaient is necessary because it hes the effect of introducinganotiner parameter whose magnitude is to be determined from the measurements thereby reducing the value of the comparison of theory and measurement. 


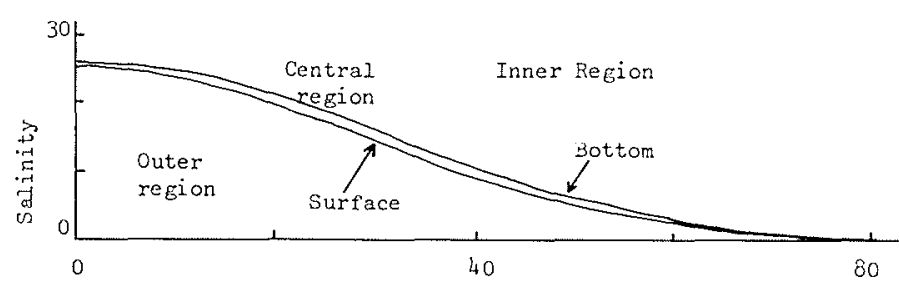

Distance from mouth

(Values given are $80-x$ where $x$ is the longitudinal co-ordinate)

FIGURE 2 LONGITUDINAL SALIBITY DISTRTEUTIOI II: TIEE DELANARE RIVER FROM PRITCIARD (WiANSEI AND RATTRAY (5), VALUES GIVEN ARE $80-x)$.

In their treatment of the outer region, Rattray and Hansen (3) assumed that

1) $K_{x}$ is zero,

2) $A, K_{z}$, and $B$ are constant,

3) the net transport $R$ is only a small part of the total circulation, so it can be ignored to a first oraeer

4) the surface salinity is prescribed

5) vertical advective salt flux is zero.

It is evident that assumption (3) is reasonable as far as momentum and water fluxes in this region are concerned but in order to create proper salinity distribution it necessitates an assumption such as (4) above. These assumptions were justified by reference to the data of Pritchard, although Table I shows that assumption (5) may not be justified.

If a new variable, $\sigma=g\left(1-\frac{\bar{S}}{S_{0}}\right)$, is introduced, where $S_{0}$ is the salinity of sea water, equations $(5.9)$ and $(5.10)$ become

$$
\begin{aligned}
& \frac{A}{B} \frac{\partial^{4} \psi}{\partial z^{4}}-\varepsilon \frac{\partial \sigma}{\partial x}=0, \\
& K_{z} \frac{\partial^{2} \sigma}{\partial z}+\frac{I}{B} \frac{\partial \psi}{\partial z} \frac{\partial \sigma}{\partial x}=0,
\end{aligned}
$$

where $E$ denotes the differential specific gravity $\mathrm{kS}_{0}$. This parameter is small compared to unity. The boundary conditions become

$$
\psi=\frac{\partial \sigma}{\partial z}=0, \frac{1}{B} \frac{\partial^{2} \psi}{\partial z^{2}}=\frac{\tau}{A p_{f}}, \quad \text { at } z=0,
$$

and

$$
\psi=\frac{\partial \sigma}{\partial z}=\frac{\partial \psi}{\partial z}=0, \text { at } z=D(x)
$$

although comparison with equations $(5.11)$ and $(5.12)$ shows that $D(x)$ is now being assumed constant.

The similarity transformation used by Rattray and Hansen is

$\psi(x, z) / B=K_{z} \xi^{\alpha+1} F(n), \sigma(x, z)=A K_{z} L_{0}^{-3} \xi^{5 \alpha+1} G(n)$, 
where $\xi=x / \mathrm{L}_{0}$, and $\mathrm{L}_{\mathrm{o}}$ and $\alpha$ are chosen so that the dimensionless variable $n=z L_{0}^{-1} \xi^{\alpha}$ varies from zero at the surface to unity at the bottom of the estuary, subject to the restriction that $\alpha$ cannot be greater than -0.4 in order to satisfy the realistic estuarine condition of increasing depth and approach of salinity to that of the ocean. This implies that the depth is $D=L_{0}^{1+\alpha} x^{-\alpha}$, and thus the boundary condition $(6.3 b)$ no longer corresponds to no slip at the bottom.

$$
\begin{aligned}
& \text { The equations for } F \text { and } G \text { are } \\
& F^{\prime \prime}{ }^{\prime}-\varepsilon\left[(5 \alpha+2) G+\alpha \cap G^{\prime}\right]=0, \\
& G^{\prime \prime}+F^{\prime}\left[(5 \alpha+2) G+\alpha n G^{\prime}\right]=0 .
\end{aligned}
$$

Approximate solutions were obtained by expanding $F$ and $G$ in powers of $\varepsilon$. The details of the solution and the comparison of it with field observations can be found in Rattray and Hansen (3). However, since the boundary conaition (6.3b) can no longer be given a physical interpretation, it is difficult to estimate the validity of the solution.

\section{In Hansen and Rattray (5) the central and the inner} regions are considered. In formulating their equations for the central region they assume that $D, A$ and $K_{z}$ do not vary along the estuary and that $K_{x}$, which is non-zero, increases seaward at a rate proportional to the river discharge velocity, i.e.

$$
\frac{d K_{x}}{d x}=\frac{R}{3 D}
$$

For mathematical simplicity they then assumed that the width, B, and all the turbulent exchange coefficients do not vary. with depth and that the river discharge, $\mathrm{R}$, is constant indicating that no tributary inflows occur.

Solutions of equations (5.9) and (5.10) are sought in the form

$$
\psi(x, z)=R \phi(n), S(x, z)=S_{0}[\nu \zeta+\theta(n)]
$$

where $\nu$ is a constant, $n=z / D, \zeta=R\left(x-x_{0}\right) / B D K_{x_{0}}$, and $x=x_{0}$ is any chosen reference section at which the average value of $S$ is $S_{0}$. Equations (5.9) and (5.10) become

$$
\phi^{\prime}{ }^{\prime \prime}+v R \alpha=0, M \theta^{\prime \prime}+v\left(\phi^{\prime}+I\right)=0,
$$

with boundary conäitions

$$
\phi(1)=\phi^{\prime}(1)=0, \quad \phi(0)=1, \quad \phi^{\prime}(0)=\mathbb{1},
$$

and any two of

$$
\begin{aligned}
& e^{\prime}(0)=0, \\
& \theta^{\prime}(1)=0, \\
& \nu+\int_{0}^{1} \phi^{\prime} \text { od } n=0 .
\end{aligned}
$$


This boundary problem is characterized by the three dimensionless parameters.

$$
\begin{aligned}
& \mathrm{T}=\frac{\mathrm{B}}{\mathrm{D}^{2} \tau} \mathrm{AR}, \\
& \mathrm{Ra}=\frac{\mathrm{k} \mathrm{S}_{\Omega} \mathrm{D}^{3}}{\mathrm{AK} \mathrm{xO}_{\mathrm{O}}} \text {, } \\
& M=\frac{K_{z} K_{x_{0}} B^{2}}{R^{2}},
\end{aligned}
$$

where $K_{x o}$ is a reference value of $K_{x}$. Hansen and Rattray interpret these as the dimensionless wind stress, the estuarine analog of the Rayleigh number, and a ratio of tidal mixing to river flow, respectively. The final parameter could be better regarded as the square of this ratio, provided that $\sqrt{K_{z} K_{x o}}$ is taken to be a typical tidal mixing coefficient.

The solutions are

$\Phi(n)=1 / 2\left(2-3 n+n^{3}\right)-1 / 4 T\left(n-2 n^{2}+n^{3}\right)-\frac{v R a}{4 \hat{\delta}}\left(n-3 n^{3}+2 n^{4}\right)$,

$\frac{\bar{s}}{S_{0}}=1+v \zeta+\frac{v}{M}\left[(n-1 / 2)-1 / 2\left(\eta^{2}-\frac{1}{3}\right)-\delta^{n} \phi \mathrm{d} n+\int_{0}^{3} f_{0}^{n} \phi \mathrm{d} n^{\prime} \mathrm{d} n\right]$.

For appropriate values of $\mathrm{T}, \mathrm{V}, \mathrm{Ra}$, and $\mathrm{M}$ these solutions agree fairly well with observations. The detailed comparison is given in the paper referred to. It is interesting to note that it is necessary to take $K_{x}$ to be a non-zero function of $x$ in order to obtain this solution. Hansen (4) had previously obtained the same solutions and also a non-similarity solution to the boundary value problem defined in Section 5 .

Hansen and Rattray also obtained a solution for the inner region by using a procedure similar to the one used in their treatment of the outer region. The resultant similarity equations are solved approximately by expanding the dependent variables in power series in $\frac{1}{\tilde{M}}$. This procedure is justified, they state, for estuaries with strong tidal currents. Again the details can be found in Hansen and Rattray (5).

\section{Conclusions}

Pritchard's model of a coastal plain estuary has been shown to be a satisfactory basis for further studies provided that the assumptions discussed above are satisfied. Pritchard's model has been develored by Rattray and Hansen who have made additional assumptions and simplifications in order to obtain their solutions.

An assumption, not made explicitly by these authors, is that the vertical salinity gradients should be very small everywhere, i.e. the estuary is slightly stratified. This may be taken in conjunction with their assumptions about the geometry to define the class of estuary under consideration. An unacceptable assumption is the neglect of river flow by Rattray and iansen (3).

The solutions of the model depend strongly on the choice 
of the forms that the turbulent transfer coefficients $A, K_{x}, K_{z}$ are assumed to have. The concept of eddy transfer coefficients does not rest on a firm theoretical basis, and the validity of their use with time mean velocity gradients, which ignore tidal currents, is questionable. However, it seems that at the present time a quantitative treatment of estuarine flow can only be attempted if these coefficients are used and are assumed to be constant or to vary in a simple manner. Thus one application of this model is to examine various possible forms of $A, K_{x}$ and $K_{z}$ to see which assumptions yield physically realistic solutions. Using very simple assumptions for the mode of vairation of A, $K_{x}$ and $K_{z}$, Rattray and Hansen have obtained quite good agreement between their solutions and Pritchard's data. Unfortunately, as is characteristic of such proolems, there is a large number of parameters whose values are subject to considerable uncertainty, thus weakening the reliability of this confirmation.

In practice it appears that solutions of the model could be applied to fill in gaps or extend the range of field measurements and to provide a useful approximation for checking against numerical solutions of more sophisticated models which should be based on a clear understanding of all the underlying assumptions and approximations.

\section{Acknowledgements}

The first author is supported by SRC fellowship. The second author is in receipt of a grant for the study of turbulence in stratified fluids from the Australian Research Grants Comnittee and was supported while at the University of Southampton by a NERC fellowship.
References

(1) PRITChARD D.it. : A study of the salt balance in a coastal plain estuary.

J. Mar. Res., $13(1954), 133$.

(2) PRITCIARD D.W. $\quad$ : The dynamic structure of a coastal plain estuary .

J. Mar. Res., 15 (1956), 33.

(3) RÁTTRAY M., Jr, \& HANSEI D.V.: A similarity solution for circulation in an estuary.

J. Mar. Res., 20 (1962), 121.

(4) Hansen D.V.

: Salt balance anà circulation in partially mixed estuaries. In Estuaries,

ed. G.H. Lauff, Publication No. 83 ,

American Association for the Advancement of Science, Wash. (1967), 45

(5) HANSEN D.V. \& RATRAY M., Jr.: Gravitational circulation in straits and estuaries.

J. Mar. Res., 23 (1965), 104.

(6) CAREROM H.r. \& PRITCHARD D.iH.: Estuaries, In The Sea. Vol. 2, ed. M.ir. Hill, Interscience, New York, (1963), 306 .

(7) ARONS A.B. \& STOMEL $\pi$. : A mixing length theory of tidal flushing. Trans. Amer. Geophys. Un., 32 (1951), 419. 
(8) IPPEX A.T. \& HARLEMAN D:R.F.: One-dimensional analysis of salinity intrusion in estuaries.

Tecti. Bull. Com. Ria. Mydraul. Us Army,

5 (1961), 52 np.

(9) ABBOTT M.R.

: Salinity effects in estuaries.

J. Mar. Res., 18 (1960), 101.

(10) EKMAN V.I.

(11) JOHNS B.

(12) BOWDEI K.F.

(13) PRITCIAARD D.W.

(24) PRITCHARD D.W.

: Ein Beitrag zur Erklärung und Berechnung des Stromverlaufs an Flussmündungen, K. Svenska Vetensk. Akad. Förh., 5 $(1899), 479$. and residual current system in a narrort channel,

Circulation and diffusion. In Estuaries, ed. G.K. Lauff, Publication No. 83 , American Association for the Advancement of Science, Nash. (1967), 15.

: The equations of mass continuity and salt continuity in estuaries, J.Mar. Res., 17 (1958), 412.

: Salinity distribution and circulation in
: On the determination of the tidal structure

Geophys. J. Roy. Astron.Soc., 20 (1970),159.

(15) INGLIS C.C. \& ALLEN F.If. : The regimen of the Thames estuary as affected by currents, salinities, and river flow.

Proc. Inst. Civil Engrs., 7 (1957), 627.

: Rijkswaterstaat, Deltadienst, Waterloopkungdige Afdeling.

- Stroom-en Chloorgehaltmemelingen op de Rotterdamse Haterweg in de periode

19 juni -4 juli 1956, rapport nr. 16 (1962).

(17) HINWOOD J.B,

- Hydrographic survey of Newcastle Harbour I.S.W., Report of N.S.W. Dept. Public Works, Sydney (1961). the Chesapeake Bay estuarine system. J. Mar. Res., 11 (1952), 106. 
Áppendix_l_- Tidal Terms

Suppose $U_{X}=\left[U_{1 x} \cos \omega(x-c t)+U_{2 x} \cos \omega(x+c t)\right] F_{X}(z)$,

$$
U_{z}=\left[U_{1 z} \cos (\omega(x-c t)+\varepsilon)+U_{2 z} \cos (\omega(x+c t)+\varepsilon)\right] F_{z}(z)
$$

which permits a progressive, standing or intermediate tide wave of small amplitude in a uniform channel withour friction (the notation for velocities and co-ordinates is the same as in the text, but other symbols apply only to this appendix).

The continuity equation is

$0=\frac{\partial U_{u}}{\partial x}+\frac{\partial U_{z}}{\partial z}=-k\left[U_{1 x} \sin k(x-c t)+U_{2 x} \sin k(x+c t)\right] F_{x}(z)$

$+\left[u_{1 z} \cos (k(x-c t)+\varepsilon)+U_{2 z} \cos (k(x+c t)+\varepsilon)\right] \quad F_{z}^{\prime}(z)$,

hence $\frac{F_{x}}{F_{z}^{i}}=\frac{U_{1 z} \cos (k(x-c t)+\varepsilon)+U_{2 z} \cos (k(x+c t)+\varepsilon)}{k\left[U_{1 x} \sin k(x-c t)+U_{2 x} \sin k(k+c t)\right]}=k$

where $K$ is a finite constant and the primes denote differentiation.

If $x=t=0$ the second of these equations can only a apply if $\varepsilon=-\frac{\pi}{2}$. Taring $\varepsilon=-\frac{\pi}{2}$

$\left(U_{1 z}-k K U_{1 x}\right) \sin k(x-c t)+\left(U_{2 z}-k K U_{2 x}\right) \sin k(x+c t) \equiv 0$.

therefore, $\quad U_{1 z}=k K U_{1 x}, \quad U_{2 z}=k K U_{2 x}$; hence $U_{z}=k K\left[U_{1 x} \sin k(x-c t)+U_{2 x} \sin k(x+c t)\right] F_{z}(z)$

and $\left\langle U_{x} U_{z}>=\frac{1}{T} \int_{t}^{t+T} U_{x} U_{z} d t\right.$

$=U_{1 x} U_{2 x} k K F_{x} F_{z} \sin 2 k x$.

Similarly $\left\langle\mathrm{U}_{\mathrm{x}} \mathrm{U}_{\mathrm{x}}\right\rangle=\mathrm{F}_{\mathrm{x}}^{2}\left(\frac{3}{2}\left(\mathrm{U}_{1 \mathrm{x}}+\mathrm{U}_{2 \mathrm{x}}\right)^{2}+2 \mathrm{U}_{1 \mathrm{x}} \mathrm{U}_{2 \mathrm{x}} \mathrm{k} \sin ^{2} \mathrm{kx}\right)$.

In the equation of motion the tidal terms appear as

derivatives and in the final equation (egn. 5.8) they should appear as

$$
\frac{\partial^{2}<U_{x}^{U} U_{z}>}{\partial z^{2}}=U_{1 X} U_{2 x} k K\left(F_{x z}^{\prime \prime} F_{z}+2 F_{x}^{\prime} F_{z}+F_{x}^{\prime} F_{z}^{\prime \prime}\right) \sin 2 k x
$$

and

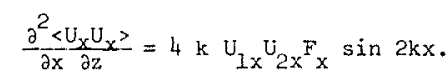

Both of these terms disappear if the tide is a pure progressive wave (i.e. if $U_{2 x}=0$ ), if there is no significant variation of tidal velocity with depth ( $F_{x}$ constant), or if the length of the tidal wave $\frac{2 \pi}{k}$ is much greater than that of the estuary. In all other cases both tiadal terms must be retained.

Agpendix 2-The Density-Pressure Product Term

The complete pressure term in the equation of motion is, in vector form.

$-\left\langle\nabla \times\left(\frac{1}{\rho} \nabla p\right)\right\rangle^{:}=\left\langle\nabla p \times \nabla \frac{1}{\rho}\right\rangle=\left\langle\nabla \vec{p} \times \nabla \frac{1}{\vec{\rho}}\right\rangle+\left\langle\nabla \frac{\rho^{\prime}}{\left(\bar{\rho}+\rho^{\prime}\right) \bar{\rho}} \times \nabla p^{\prime}\right\rangle$. 
The first term on the right hand side has already been considered, the second term. involves the product of derivatives of density and pressure fluctuations. In the $y$ direction the latter term becores

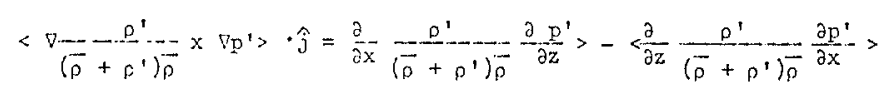

$=\frac{1}{\rho^{2}}-\frac{\partial \rho^{\prime}}{\partial x} \frac{\partial p^{\prime}}{\partial z}-\frac{\partial \rho^{\prime}}{\partial z} \frac{\partial p^{\prime}}{\partial x} \rightarrow$

Iilus term of higher order in $\rho / \rho$.

Applying mixing lengths ideas, a density fluctuation may be regarded as the result of a circuiar eddy acting mean density gradients, hence typical values for a slightly stratified estuary are

$$
\frac{\partial \rho^{\prime}}{\partial z}-\frac{\partial \rho^{\prime}-}{\partial x^{-}}-\frac{\partial \bar{\partial}}{\partial x}-\rho_{0} k S_{0} / L
$$

The pressure at a noint will fluctuate if the average density of the water above it fluctuates. Assuming that an eddy of diameter up to $D$ and density differential $\rho$ ' passes over the point in question, the pressure will fluctuate an amount $F^{\prime} \leq \rho \rho^{\prime} D$, and the gradients will nave the values

$$
\frac{\partial F^{\prime}}{\partial x} \sim \frac{\partial N^{\prime}}{\partial z} \sim \rho^{\prime} \xi-g \rho_{0} K S_{O} / \bar{L} .
$$

Thus the fluctuation term is of the order of $f\left(\frac{k}{L}-\frac{S_{0}}{2}\right)^{2}$, whereas the gravitational term in the equation of motion is of order $g\left(\frac{k S_{0}}{L D}\right)$. Since both $k S_{o}$ and $D / L$ are small quantities the neglect of the fluctuation term appears to be reasonable witnout the need to assure that $\rho^{\prime}$ and $p^{\prime}$ are uncorrelated. 
ON ROW IN ESTUMTILO

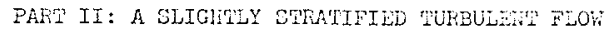

\section{I.- IMTROLUCHIOH.}

Flow in a tro-àimensional channel of uniform cepth is considereà. rine flor is assured to be incompressibie but non-horioceneous due to differences in any conservative property, although for convenience the particular exariple of a horizontal ciannel containine water of varying salinity will ve aescribea. Through the action of turiulence, vertical anô horizontal mixine occur, and in aaäition convective fluxes of salt nay occur.

An important exarple of this idealised flow is the coastal

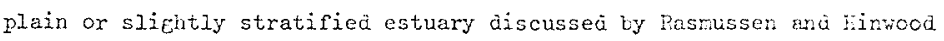
(1) - referred to as Part I - and by Pritchard (2), liansen ( 3 ), iansen and Rattray (4) and many others. River water enters the estuary at one end and sea water at the other end, preäominantly at the bottor. lixing occurs mainiy over the central reeion of the estuary, and the salinity satisfies boundary concitions at both ends of the estuary.

In this peper we show that it is not possible for the flow to be two-dimensional and slightly stratifiec, the channel to be of constant depth and the turbulent aiffusion to be expressec by eady diffusion coefficients. Some or all of these conditions have been though in this paper we a not atter:pt to propose improved rodels, it was felt that a careful analysis of the Iimitations of the models presently in use would be of value. We will present an analysis of more general models in a later paper.

\section{Forriulation}

Whe protlen will be formulatea ana analysea in its simplest forn for clarity; then some important eneralizations will be treatea. The turbulent incompressible flow in a chanel of a non-homo-

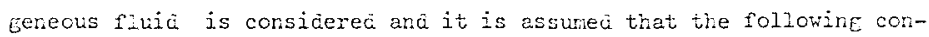
ciitions are satisfieć:

(i) The time-rean velocity and salinity are tro-äimensional.

(ii) the cepth of the chamel, D, is constant.

(iii) The fllow is slightiy stratifieä.

(iv) The aiffusive mixine may be attributed to the effects of ciffusion coefficients which are functions of position. By the thiri conciation we mean that the vertical salinity gradient is small at any point and that the salinity throughout the channel may be represented by a function of the loneituainal coorainate only plus a small ceviation which is a function of both position cooräinates.

We shall now show that these four conditions cannot all be satisfied simultaneousiy. We do this by assurning that they are satisfied, and then by integration of the salt conservation equation we 
obtain a contradiction. It is not necestary to make any detailed assumption about the dynamics of the flow. Both steady and unsteady flows are considered, but the boundary conditions are taken as steaôy in both. cases for reasons given later.

Let $x_{1}$ be the horizontal coordinate measured 'along the channel with its origin so chosen that the mixing mainly takes, place between $x_{1}=-L$ and $x_{1}=L$. We shall later discuss the different cases which arise from the different magnitudes of the ratio $D / L$. Let $z_{1}$ be the vertical coordinate taken positive downwards and with the origin at the surface.

At the ends of the channel we can suppose that the flow is uniform and that the derivative of the salinity with respect to $x_{1}$ tends to zero as $x_{1} \rightarrow \pm \infty$. Since we are consiaering the mixing of fresh. and salt water it can also be supposed that the salinity. is not constant throughout the channel. This density difference causes an inflow of saltwater into the mixing region $\left|x_{1}\right|<L$, and in order to keep this region stationary it is necessary to suppose a forcea inflow of freshwater at the rate $R$, say, in the direction of positive $x_{1}$. The stratification is then caused by the partial mixing due to the turbulence of these two streams of fluid.

The turbulent salt conservation equation, which was given

in Part I, is

$$
\begin{aligned}
\frac{\partial \bar{S}}{\partial t_{1}}=\frac{\partial \psi}{\partial z_{1}} \frac{\partial \bar{S}}{\partial x_{1}}-\frac{\partial \psi}{\partial x_{1}} \frac{\partial \bar{S}}{\partial z_{1}} & +\frac{\partial}{\partial x_{1}}\left(G\left(x_{1}, z_{1}, t_{1}\right) \frac{\partial \bar{S}}{\partial x_{1}}\right) \\
& +\frac{\partial}{\partial z_{1}}\left(H\left(x_{1}, z_{1}, t_{1}\right) \frac{\partial \bar{S}}{\partial z_{1}}\right) .
\end{aligned}
$$

Here the time mean salinity is $\bar{S}$ and the time mean strean function $\psi$ identically satisfies the two-dimensional continuity equation. In obtaining this expression the following assumptions were mace:

(1) Molecular diffusion is negligible compared with turbudent diffusion.

(2) The flux of salt due to turbulence may be represented by the product of the mean salinity gradient anci an eaddy diffusion coefficient, $G$, in the $x$ direction and $I f$ in the $z$ direction.

(3) All quantities are assumed to be independent of the transverse coordinate.

(4) Time means of procucts of tical terms are zero as are time means of tidal" and turbulence terms.

Boundary conditions at the surface and the bottom of the channel which ensure conservation of water and salt are

$$
\begin{aligned}
& \text { at } z_{1}=0 \quad \psi=R, \frac{\partial \bar{S}}{\partial z_{1}}=0 ; \\
& \text { at } z_{1}=D \quad \psi=0, \frac{\partial \bar{S}}{\partial z_{1}}=0,
\end{aligned}
$$

where $R$ is the net flux of water per unit. breadth, i.e. the river discharge per unit breadth. At the enòs of the channel we have the folLowine conditions on $\bar{s}$ 


$$
\frac{\partial \bar{S}}{\partial x_{1}}+0 \quad \text { as } \quad x_{1} \rightarrow \pm \infty \text {, }
$$

and that $\frac{\partial \bar{S}}{\partial x_{1}}$ is not identically zero throughout the channel. From the condition that the flow is uniform at the ends of the channel we have

$$
\frac{\partial \psi}{\partial x_{1}}+0 \text { as } x_{1}+ \pm \infty \text {. }
$$

To normalize the problem consistine of (2.1) to $(2.4)$. we at first assume that the significant length scales for changes in $\vec{S}$ and $\psi$ are equal anō later treat the case of unequal scales. Thus we define non-äimensionel coorainates $x$ and $z$ and variables as foliows:

$$
\begin{aligned}
x_{1} & =\bar{L} x, \\
z_{1} & =\mathrm{D} z, \\
t_{1} & =t_{0} t, \\
\psi\left(x_{1}, z_{1}, t_{1}\right) & =\psi_{0} \phi(x, z, t), \\
\bar{S}\left(x_{1}, z_{1}, t_{1}\right) & =S_{0} e(x, z, t), \\
G\left(x_{1}, z_{1}, t_{1}\right) & =K_{x} g(x, z, t), \\
N\left(x_{1}, z_{1}, t_{1}\right) & =K_{z} h(z, x, t)
\end{aligned}
$$

where the subscript $O$ indicates a suitable reference quantity and $K_{x}$ and $K_{z}$ are reference values of $G$ ana $I$. Equation (2.1) now becomes

$$
I^{1} \frac{\partial \theta}{\partial t}=-\frac{\partial \phi}{\partial x} \frac{\partial \theta}{\partial z}+\frac{\partial \phi}{\partial z} \frac{\partial \theta}{\partial x}+x \frac{\partial}{\partial x}\left(E \frac{\partial \theta}{\partial x}\right)+z \frac{\partial}{\partial z}\left(n \frac{\partial \theta}{\partial z}\right)
$$

and the bounàary conàitions $(2.2)$ ana $(2.3)$ are satisfiec if

$$
\begin{aligned}
& \frac{\partial \theta_{n}}{\partial z}=0 \text { at } z=0, \quad 1 \text { for } n \geqslant 1, \\
& f^{\prime}(x, t)+0, \frac{\partial \theta_{n}}{\partial x}+0 \text { for } n \geqslant 1
\end{aligned}
$$

as $x+\infty$, and

$$
f^{\prime}(x, t)+0, \frac{\partial \theta_{n}}{\partial x}+0 \text { for } n \geqslant 1
$$

es $x \rightarrow-\infty$. Also $f^{\prime}(x, t)$ is not icentically zero for $-\infty<x<\infty$.

The stream function $\phi$ may also be expanciea in terms of a

$$
\phi(x, z, t)=\phi_{0}(x, z, t)+\sum_{n=1}^{\infty} \alpha^{n} \phi_{n}(x, z, t)
$$

with the boundary conditions (2.2) and (2.3) becoming 
$\phi_{0}=R / \psi_{0}$ at $z=0, \phi_{0}=0$ at $z=1$,

$\phi_{\mathrm{n}}=0$ at $z=0,1$ for $n>1$,

and

$$
\frac{\partial \dot{\varphi}}{\partial x}+0 \text { as } x+ \pm \infty \text { for } n \geqslant 1
$$

The expansion (2.10) implies that the presence of slight vertical stratification causes an equally slight modification to the streamline patterns which is unlikely to be true unless $\alpha$ is extremely small. In section 4 this restriction will be renoveć.

In the next two sections steady flows are considered; in section 3 steady flows with equal leneth scales for salinity aná stream function and in section 4 other steady flows. The latter comprise steaay flows with unequal leneth scales for salinity and stream function, flows in which the snall vertical stratification causes a large change in stream function and finally steady flows in a channel of gradually varied depth. In section 5 the restriction of steady flow is removed and two types of flow are considered: flows in which the salinity is steady to first order and flows in which the salinity is unsteacy to first orceer. These examples incluce most of the cases occurring in estuarine flows; some of the cases omittea are considered in the final section.

\section{Steaiy Flow with Equal Length Scales}

The basis of the analysis is to assume that the four conditions stated in section 2 are satisfied and then by integration of the linearized salt conservation equation obtain a contradiction.

We substitute expansions $(2.6)$ and $(2.10)$ into the steady form of equation (2.5) and retain only terms of order $\alpha^{\circ}$. At the moment we do not wish to make any assumptions about the magnitudes of $x$ and $z$ except that both convective anc âiffusive terms shoula be present in the linearized approximate equation. lience we have

$$
-f^{\prime}(x) \frac{\partial \phi_{0}}{\partial z}=x \frac{\partial E f^{\prime}(x)}{\partial x}+\alpha z \frac{\partial}{\partial z}\left\langle h \frac{\partial \theta_{1}}{\partial z}\right\rangle
$$

with boundary conaitions given by $(2.7)$ to $(2.9),(2.11)$ ana (2.12). From this equation we see that in this model of slightly stratified flow only horizontal convection of salt is retained. The vertical convection is of lower order.

Dependinf on the magnitudes of $X$ and $z$ there are three nontrivial cases to be considered.

$$
\begin{aligned}
& \text { Case } 1 \quad x=0(1), z=0(1) ; \\
& \text { Case 2 } x=0(1), z=0\left(\alpha^{-1}\right\} \\
& \text { Case } 3 \quad x=0(\alpha), z=0\left(\alpha^{-1}\right)
\end{aligned}
$$

From the definitions of $x$ and $z$ given in the previous sec-

tion we have 


$$
\frac{X}{Z}=\frac{K_{X}}{K_{z}}\left(\frac{D}{L}\right)^{2}
$$

Thus if we suppose that the ration $\mathrm{K}_{\mathrm{X}} / \mathrm{K}_{\mathrm{z}}$ is of order 1 , the first case implies that the depth of the channel and the length of tile mixing region are of the same order of magnitude, while for the second and thiri cases the length of the mixing region is greater, by several order of magnitudes, than the depth of the channel. For application to the flow in sliehtly stratified estuaries the second case is uncioubtedly the more realistic one.' We obtain, however, the sare result from the analysis of each of the three cases.

Case 1.

$$
\begin{aligned}
& \text { Equation (3.1), reduces to } \\
& f^{\prime}(x) \frac{\partial \phi_{0}}{\partial z}=x \frac{\partial}{\partial x}\left(g^{\prime}(x)\right) .
\end{aligned}
$$

When this equation is integrated with respect to $z$, we obtain

$$
-f^{\prime}(x) \phi_{0}(x, z)=x \int_{0}^{z} \frac{\partial}{\partial x}\left[\tilde{E}(x, z) f^{\prime}(x)\right] \hat{a} z+F_{0}(x)
$$

Since from $(2.11) \phi_{0}=R / \psi_{0}$ at $z=0$ and $\phi_{0}=0$ at $z=1$,

$$
-\frac{R}{\psi_{0}} f^{\prime}(x)=F_{0}(x)
$$

and

(3.3) may be interchanged following Leibnitz's rule provided that $g(x, z)$, $f^{\prime}(x)$ and $\frac{\partial}{\partial x} g(x, z) f^{\prime}(x)$ are continuous in both $x$ and $z$ for $-\infty<x<\infty$ and $0 \leq z \leq 1$. In flows of the type we are considering these conditions are met, ana thus we may exchange the order of the operations and then integrate with respect to $x$ to obtain

$$
\int_{0}^{1}\left[g(x, z) f^{\prime}(x)\right] d z-\frac{R}{X \psi_{0}} f(x)=c_{0}
$$

where $C_{0}$ is a constant. This equation nay be written in the form

$$
f^{\prime}(x)-\alpha P(x) f(x)=C_{0} P(x)
$$

where $\alpha=\frac{R}{X \psi_{0}}$, and

$$
P(x)=\left[\int_{0}^{1} E(x, z) d z\right]^{-1} .
$$

Since $\alpha$ is non-zero, the solution to equation $(3.4)$ is 


$$
f(x)=C_{1} \exp \left[\alpha \int_{0}^{x} P(\mu) d \mu\right]-\frac{C_{0}}{\alpha}
$$

where $C_{1}$ is a constant. Hence

$$
f^{\prime}(x)=C_{1} \alpha P(x) \exp \left[\alpha \int_{0}^{x} P(\mu) \alpha \mu\right]
$$

Since $g(x, z)$ is positive and finite, $P(x)$ is positive and finite. Hence $f^{\prime}(x)$ as given by (3.5) cannot satisfy either of the boundary conditions $(2.8)$ and $(2.9)$, i.e. $f^{\prime}(x)$ cannot tend to zero as $x+ \pm \infty$, Thus we have obtainea a contradiction and must conclude that the four conditions stated in section 2 cannot all be satisfied for case 1 .

Case 2.

For this case $X$ and $Z$ are both of order 1 , and if we set $\alpha z=\lambda$, equation $(3.1)$ can be written as

$$
-f^{\prime}(x) \frac{\partial \phi_{0}}{\partial z}=x \frac{\partial}{\partial x}\left(g f^{\prime}\right)+\lambda \frac{\partial}{\partial z}\left(h \frac{\partial \theta_{1}}{\partial z}\right) .
$$

When we integrate over the depth, we get

$-f^{\prime}(x) \phi_{0}(x, z)=x \int_{0}^{z} \frac{\partial}{\partial x}\left(g f^{\prime}\right) d z+\lambda\left(h \frac{\partial \theta_{1}}{\partial z}\right)+F_{1}(x)$.

From (2.7) we have that $\frac{\partial \theta_{1}}{\partial z}=0$ at $z=0,1$, and since $h(x, z)$ is finite, equation (3.6) reduces to (3.3). Thus we obtain the same conclusions as for case 1.
Case 3.

In this case $x=O(\alpha)$ and $\alpha z=O(1)$ and with $\alpha z=\lambda$, equation (3.1) becomes

$$
-f^{\prime}(x) \frac{\partial \phi_{0}}{\partial z}=\lambda \frac{\partial}{\partial z}\left(h(x, z) \frac{\partial 0_{1}}{\partial z}\right)
$$

By integration with respect to $\mathrm{z}$ and application of the boundary condi-

tions $(2.7)$ and $(2.11)$ at $z=0$ we have that

$$
f^{\prime}(x) \equiv 0
$$

This implies that the salinity to the first order is constant, and since we are considering the mixing of fresh and salt water, it must be rejected. Thus we reach the same conclusions as for cases 1 and 2 .

In this section and in the next section only one of the condi tions $f^{\prime}(x)+0$ as $x+ \pm \infty$ is required. Thus the results of these sections are directly relevant to estuaries.

\section{Other Steady Flows}

The basic case of steady flow presented above may be extended to several cases of relevance to real estuaries. The first of these arises from the observation that the salinity (or temperature) variation tends to be concentrated in a thin layer to an even greater degree than the velocity variation. Thus a smaller length scale, say $D_{1}$, may be appropriate for 
salinity. Writine $n=2 / D_{1}$ the steady form of equation. (2.5) now becomes

$$
\frac{\partial \phi}{\partial x} \frac{\partial \theta}{\partial n} \frac{D}{D_{1}}-\frac{\partial \phi}{\partial z} \frac{\partial \theta}{\partial x}=x \frac{\partial}{\partial x}\left(g \frac{\partial \theta}{\partial x}\right)+z\left(\frac{\mathcal{D}}{D_{1}}\right)^{2} \frac{\partial}{\partial n}\left(h \frac{\partial \theta}{\partial n}\right)
$$

and hence retaining terms of order $\alpha^{\circ}$ and those containinE $\alpha\left(D / D_{1}\right)$

$\frac{\partial \phi_{0}}{\partial x} \frac{\partial \theta_{1}}{\partial \eta} \frac{D}{D_{1}} \alpha-\frac{\partial \phi_{0}}{\partial z} f^{\prime}(x)=x \frac{\partial}{\partial x}\left(g f^{\prime}\right)+z\left(\frac{D}{D_{1}}\right)^{2} \alpha \frac{\partial}{\partial \eta}\left(h \frac{\partial \theta_{1}}{\partial \eta}\right)$.

The limited data available suggest that for the estuaries being consicered $D / D_{1}-2$. Thus the restriction that $\alpha\left(D / D_{1}\right)^{2}=O(I)$ may be imposed and hence the first term may be neglected but the final term must be retained, a result supported by the data of Pritchard (2).

$$
\text { Let } Z\left(D / D_{1}\right)^{2} \alpha=\lambda \text {. Then equation }(4.2) \text { becomes }
$$$$
-f^{\prime} \frac{\partial \phi_{0}}{\partial z}=x \frac{\partial}{\partial x}\left(g f^{\prime}\right)+\lambda \frac{\partial}{\partial \eta}\left(h \frac{\partial \theta}{\partial \eta}\right) \text {. }
$$

The final term disappears on integration over the depth and equation (3.2) is again obtained, leading to the same conclusions.

The second extension to the basic steady flow analysis is to permit the stream function to change significantly for small changes in salinity.

In writing equation (2.10) it was assumed that the small stratification $\sum_{n=1}^{\infty} \alpha^{n} \theta_{n}(x, z)$ produced a flow with correspondingly small changes in the stream function, $\sum_{n=1}^{\infty} \alpha^{n} \phi_{n}(x, z)$. If instead it is assumed that the change is of first orier, equation (2.10) is replaced by

$$
\phi(x, z)=\phi_{0}(x, z)+\sum_{n=1}^{\infty} \sum_{n=1}^{n} \alpha_{n}(x, z)
$$

where $\alpha^{\alpha} \alpha=\beta=0(1)$, then the followine term must be aaded to the left side of equation (3.2): $-\beta . f^{\prime} \frac{\partial \phi_{1}}{\partial z}$. On integration of tinis term with respect to $z$ and the application of the boundary conditions (2.7) and (2.11) it vanishes. Equation (3.3) and the conclusions are thus unaltered.

As the final extension to the steady flow case, the case of flow in which the depth varies gradually along the channel will now be considered.

From (2.5) we see that the governing equation for this

case is

$$
-\frac{\partial \phi}{\partial z} \frac{\partial \theta}{\partial x}+\frac{\partial \phi}{\partial x} \frac{\partial \theta}{\partial z}=x \frac{\partial}{\partial x}\left(\varepsilon \frac{\partial \theta}{\partial x}\right)+z \frac{\partial}{\partial z}\left(h \frac{\partial \theta}{\partial z}\right) .
$$

If we linearize this equation as before, we have

$$
-f^{\prime}(x) \frac{\partial \phi_{0}}{\partial z}=x \frac{\partial}{\partial x}\left(g f^{\prime}(x)\right)
$$

where it is supposed that $X$ and $Z$ are both $0(1)$. This equation can be written in the form 


$$
f^{\prime \prime \prime}(x)=\left[\frac{C}{X_{E}}-\frac{B F_{x}}{E}\right] f^{\prime}(x)
$$

where

$$
\begin{gathered}
\sigma(x, z)=-\frac{\partial \phi_{0}}{\partial z}, \\
\mathcal{E}_{X}=\frac{\partial E}{\partial x} .
\end{gathered}
$$

If we inteerate once, we tet

$$
f^{\prime}(x)=\frac{f^{\prime}(0) E(0, z)}{E(x, z)} \exp \left\{\int_{0}^{x} \frac{\sigma(x, z)}{\partial E(x, z)} d x\right\}
$$

$\Lambda$ similar result can be àerivea in a different way. Suprose that there is no vertical diffusion near $z=0$. sthen at $z=0$, equation $(4.3)$ reduces to

$$
u_{x} \frac{\partial \theta}{\partial x}=x \frac{\partial}{\partial x}\left(g \frac{\partial e}{\partial x}\right)
$$

since $u_{z}=\frac{\partial \varphi}{\partial x}=0$ at $z=0$. Finis equation can be integratec to give

$$
\frac{\partial U}{\partial x}=\frac{h_{.}}{E(x, U)} \operatorname{exI}\left\{\frac{1}{x} \int_{0}^{x} \frac{u_{x}(x, 0)}{E(x, 0)} d x\right\}
$$

where

$$
K=\left.g(0,0) \frac{\partial 0}{\partial x}\right|_{x=0} .
$$

Fivo conclusions can be drewn from (4.5) and (4.6). Firstly since $f^{\prime}(x)$ and $\frac{\partial \theta}{\partial x}$ rust tend to zero as $x+\infty$ the integrals must be negative at some parts of the channel. Now if the reservoir of salt water is at $x=\infty$, the horizontal surface velocity is positive and hence $\sigma(x, 0)$ is positive. Thus if $g(x, 0)$ is positive, $f^{\prime}(x)$ and $\frac{\partial \theta}{\partial x}$ cannot tend to zero. Seconàly, if $g(x, z)$ in $(4.5)$ or $g(x, 0)$ in $(4.6)$ become negative, $O(x, z)$ and $u_{x}(x, 0)$ must also become negative in such a way that the quantities

$$
\frac{\sigma(x, z)}{\varepsilon(x, z)} \text { and } \quad \frac{u_{x}(x, 0)}{E(x, 0)}
$$

do not tenà to infinity. Otherwise $f^{\prime}(x)$ and $\frac{\partial \theta}{\partial x}$ woulä become infinite. thiese resuits are ciearly unacceptable on physical Erounàs.

$$
\text { We notice that the expressions }(4.5) \text { and }(4.6) \text { can only be }
$$
obtained if the vertical diffusive tern can be removed from equation (4.3).

\section{3. insteady Flows}

The possibility that the conservation equations anc the steaà bouncary conditions mi ght be satisfiea by an unsteady flow was sugcesti: by anaiogy with the jet streams. The jet streams, through their ursteauy meancering, transport momenturi in a direction perpenciicular to their mean motion balancing advective and other processes and satisfying conservation of momentum. A closer analogy is the salt weage, which has been observed in the laboratory to advance and retreat without any measurable unsteadiness in the inflow or outflow conditions (Riduell, personal communication, 2971) each retreat beine rarked by a major increase in the aownstream transport of salt by the upper layer. 
Both time independent and time dependent zero order profiles are considerea and in each case the higher order terms and the diffusion coefficients are allowed to vary with time. Considering first the case of steaciy zero order salinity, $f$ in the expansion (2.5) is taken as a function only of $x$.

\section{For Ereater generality we suppose that}

$$
\alpha \mathrm{T}=\mu=O(1), \quad \alpha Z=\lambda=O(1) .
$$

'ihen the linearized equation becomes

$$
\mu \frac{\partial \theta_{1}}{\partial t}=f^{\prime}(x) \frac{\partial \phi_{0}}{\partial z}+X \frac{\partial}{\partial x}\left(g f^{\prime}(x)\right)+\lambda \frac{\partial}{\partial z}\left(h \frac{\partial \theta_{1}}{\partial z}\right)
$$

with boundary conditions as in section 2 .

If we integrate equation (5.1) with respect to $z$ and impose the bounaary conaitions at $z=0,1$ we obtain

$$
\mu \int_{0}^{1} \frac{\partial \theta_{1}}{\partial t} d z=-\frac{R}{\psi_{0}} f^{\prime}(x)+x \int_{0}^{1} \frac{\partial}{\partial x}\left(g f^{\prime}(x)\right) d z
$$

As before we assume that the integrands are continuous in $x, z, t$ for $-\infty<x<\infty, 0 \leq z \leq 1,0 \leq t<\infty$ so that the order of integration and differentiation may be exchanged. Hence $(5.2)$ becomes

$$
\mu \cdot \frac{\partial}{\partial t} \int_{0}^{1} \theta_{1} d z=-\frac{E_{i}}{\psi_{0}} f^{\prime}(x)+x \frac{\partial}{\partial x} f^{\prime}(x) \int_{0}^{1} g(x, z, t) d z .
$$

This equation is integrated with respect to $x$ and arain the crier of integration and differentiation is exchanged. Hence

$\mu \frac{\partial}{\partial t} \int_{-\infty}^{x} d x \int_{0}^{1} \theta_{1} d z=-\frac{\mathbb{R}}{\psi_{0}} f(x)+X f^{\prime}(x) \int_{0}^{l} E(x, z, t) d z+H(t)$

where $H(t)$ is an unknown function. Ey application of the bouncary condition at $x=-\infty$ we see that

$$
I I(t)=\frac{R}{\psi_{0}} f(-\infty),
$$

and since $f^{\prime}(x)+0$ as $x+\infty$

$$
\mu \frac{\partial}{\partial t} \int_{-\infty}^{\infty} d x \int_{0}^{1} \theta_{1} \mathrm{~d} z=\frac{R}{\psi_{0}}[f(-\infty)-f(\infty)] .
$$

Thus

$$
\int_{-\infty}^{\infty} d x \int_{0}^{1} \theta_{1} d z=\frac{R}{\psi_{0}^{\mu}}[f(-\infty)-f(\infty)] t+A
$$

where $A$ is a constant.

The left hand sicie is the total amount of salt in the channel due to $\theta_{1}$, and since $f(-\infty)-f(\infty)$ must be nonzero, the expression indicates that it becomes infinite as $t \rightarrow \infty$. Thus we have ottanned tine required contradiction

liow if $T=O(I)$ equation $(5.1)$ becomes 


$$
0=f^{\prime}(x) \frac{\partial \phi_{0}}{\partial z}+x \frac{\partial}{\partial x}\left(g f^{\prime}(x)\right)+\lambda \frac{\partial}{\partial z}\left(h \frac{\partial \theta_{1}}{\partial z}\right) .
$$

This case has been treated in section 3 where it was shown that the four conditions cannot all be satisfiea.

In the second case of unsteady flow to be considered the zero order salinity is permitted to be unsteady.

If we set $\alpha Z=\lambda=O(1)$ we obtain the following Iinearized

equation

$$
y \frac{\partial f}{\partial t}=\frac{\partial f}{\partial x} \frac{\partial \phi_{0}}{\partial z}+x \frac{\partial}{\partial x}\left(\varepsilon \frac{\partial f}{\partial x}\right)+\lambda \frac{\partial}{\partial z}\left(h \frac{\partial \theta_{1}}{\partial z}\right) .
$$

As above we integrate with respect to $z$ and impose the bounaary conaitions at $z=0,1$. Thus

$$
{ }^{T} \frac{\partial f}{\partial t}=-\frac{F}{\psi_{0}} \frac{\partial f}{\partial x}+x \int_{0}^{1} \frac{\partial}{\partial x}\left(g \frac{\partial f}{\partial x}\right) \dot{d} z .
$$

iftain we suppose that the oraer of integration and differentiation can be exchanged. After integration with respect to $x$ we obtain

$$
{ }^{\prime \prime} \int_{-\infty}^{x} \frac{\partial f}{\partial t} d x=-\frac{\bar{z}}{\psi_{0}} f(x, t)+x \frac{\partial f}{\partial x} \int_{0}^{l} g d z+F(t)
$$

wite $F(i)$ is an unknown function of t. Since

$$
\begin{aligned}
& \frac{\partial f}{\partial x} \rightarrow 0 \quad \text { as } x \rightarrow-\infty, \\
& F(t)=\frac{K}{\psi_{0}} P(-\infty, t) .
\end{aligned}
$$

Thus we have

$$
\frac{\partial}{\partial t} \int_{-\infty}^{\infty} f(x, t) \dot{a} x=\frac{R}{F^{2} \psi_{0}}[\mathbf{f}(-\infty, t)-f(\infty, t)],
$$

since

$$
\frac{\partial \boldsymbol{f}}{\partial x}+0 \quad \text { as } x \rightarrow \infty \text {. }
$$

Therefor

$$
\int_{-\infty}^{\infty} f(x, t) d x=\beta_{1} t+\hat{b}_{0}
$$

where $B_{0}=$ constant, and

$$
B_{1}=\frac{R}{\sum \psi_{0}}[f(-\infty, t)-f(\infty, t)]
$$

$B_{1}$ is also constant since we have supposed that the salinity anci streamfunction ào not depend on $t$ at the enàs of the channel.

$$
\text { This result shows that the salt in the channel due to }
$$

$f(x, t)$ is unbounded, ano this we have obtained the required contradiction. 
6. Discussion of Results

The result obtained is that from consideration of the kinematics and salt conservation a flow cannot be two-dimensional, slightly stratified, with turbulent mixine described by eddy aiffusion coefficients, steady and of constant depth; and the same result has been shown to hold with the last two restrictions removea separately. This result has consequences in the formulation of mathematical models of estuarine and other flows which will now be considered.

Estuarine flows, other tỉan sharply stratificã cases, have. been mathematically mocielled one-dimensionally by many workers, but twodimensional stuaies are all but non-existent. For this reason alone the analyses of Hansen (3) and Hansen and Rattray (4) are of great interest. fansen consiuerea an estuarine flow satisfying the above conoitions, as did liansen and Rattray except that for their solution for the inner reEion they stipulated an exponential or power law variation of the breacth ana äepth with $x_{1}$. To solve the equations they were obligea to impose aciaitional conäitions which restricted the valiciity of their solutions to particular reaches of the estuary. It would be expectec that these restricted solutions could be matched at their ends to give a composite solution for the whole estuary. However, the result obtained here shows that the assumptions underlying each of their solutions obtainec with constant aepth and breadith cannot be applieà to the whole estuary so that a composite solution appears to be unobtainable. lience any improvement upon the pioneering work of Hansen ana Rattray, or any newly derivea mathematical models must be based upon some other set of conditions.

It is temptine to speculate on why such an apparently reasonable, if idealized, model should lead to contradictions and with the hope of improvine this model each major assumption will be examined in turn. Firstly the assumption of two-àimensional flow, although possibly questionable in a real estuary, can ve expected to occur in a laboratory channel. Secondiy, the use of eddy diffusion coefficients appears reasonable here, although it does not rest on a souna theoretical basis. This is because no assumptions were made about the form of the coefficients other than to assume that they are Greater than zero, i.e. that turbulence woula carry more salt from a region of high salinity to one of low salinity than in tile opposite direction. File conaitions of steaäy flow anà constant depth were relaxea separately ana so are unlikely to be responsible for the contradiction.

This leaves the assumption of slight stratification throughout the interior of the estuary and at one end boundary as the most likely fault in the mociel. Field ana laboratory stuäies now in progress should resolve this point, but whatever the fault it is clear that a rigorous dexivation of a mathematical model of estuarine flow is neeâd and this will form the subject of a later paper in this series. 
Acknowle deements

The first author was supported by a Monash University

Kesearch Fellowship and is now supported by a SRC fellowship. The second author is in receipt of a grant for the study of turbulence in stratified fluids from the Australian Research Grants Committee and was supported while at the University of Southampton by a NERC fellowship.

References

(1) RASMUSSEN H \& HINKOOD J.B. : On flow in estuaries, Part I. A critical review of some studies of slightly stratified estuaries.

To appear in La Houille Blanche.

(2) PRITCHARD D. i.

: A study of the salt balance in a coastal plain estuary.

J. Mar. Res., 13 (1954), 133.

(3) HaNSGiv $D . V$.

: Salt balance and circulation in partially mixed estuaries. In Estuaries, ed. G.Hi. Lauff, Publication No. 83, American Assocoation for the Advancement of Science (1967), Wash. pp. 45-51.

(4) HANSEN D.V. \& RATTRAY M., Jr.: Gravitational circulation in straits and estuaries.

J. Mar. Res. 23 (1965), 104 